\title{
Candidiase vulvovaginal: fatores predisponentes do hospedeiro e virulência das leveduras
}

\section{Vulvovaginal candidiasis: susceptibility factors of the host and virulence of the yeasts}

Cassiana Aparecida Álvares'; Terezinha Inez Estivalet Svidzinski²; Márcia Edilaine Lopes Consolaro³

unitermos
Candidíase vulvovaginal
Candida albicans
Fatores predisponentes
Fatores de virulência

Fatores de virulência

\section{resumo}

Introdução: Leveduras do gênero Candida são patógenos oportunistas freqüentemente isolados das superfícies mucosas de indivíduos normais, mas podem levar ao desenvolvimento de infecções denominadas candidíases, que variam desde lesões superficiais até infecções disseminadas. Objetivos: Ampliar os conhecimentos sobre candidíase vulvovaginal (CVV: infecção de vulva e vagina, causada por leveduras comensais que habitam a mucosa vaginal) e candidíase vulvovaginal recorrente (CVVR: ocorrência de quatro ou mais episódios de CVV no período de 12 meses), bem como caracterizar e abordar o ponto de vista das influências do hospedeiro e dos fatores de virulência dos agentes causais da infecção, principalmente C. albicans, visando identificar a sua importância nessa patologia. Tanto fatores predisponentes locais como sistêmicos do hospedeiro podem contribuir para a invasão por Candida sp. Sua intensa multiplicação no canal vaginal é favorecida por uma série de fatores predisponentes abordados nesta revisão. Também tem sido postulado que existem diferenças na patogenicidade de isolados de Candida sp., não sendo o fungo apenas um participante passivo no processo infeccioso; com isso vários fatores de virulência têm sido propostos e são descritos. Discussão e conclusões: Este artigo de revisão bibliográfica buscou atualizar os profissionais da área da saúde em relação a CVV, CVVR, aspectos predisponentes do hospedeiro e virulência dos agentes causais, que são pouco conhecidos. Assim, a atualização e o conhecimento de conceitos básicos e clínicos relacionados com essa patologia são muito importantes para auxiliar o seu manejo pelos profissionais da área.

\footnotetext{
Introduction: Vulvovaginal candidiasis (VVC) is a vulva and vagina infection caused by comensal yeasts that inhabit the vaginal mucosa and eventually become patogenic, depending on host conditions. Eighty percent to $90 \%$ of the infections are due to C. albicans, and $10 \%$ to $20 \%$ to other species called non-C. albicans (C. tropicalis, C. glabrata, C. krusei, C. parapsilosis, C. pseudotropicalis, C. lusitaniae). C. glabrata is the second agent in frequency in VVC and yeasts of other genus can also cause this infection, as Saccahromyces cerevisiae, Rhodutorula sp. and Trichosporon sp. Besides host inherent factors, it has been postulated that differences exist in the patogenicity of different isolates of Candida sp. The fungus is not a mere passive participant in the infectious process, and a series of virulence factors has been proposed, but little was investigated in VVC. The objective of this work is to enlarge knowledge on VVC and RVVC, as well as to discuss the influences of host and virulence factors, aiming to identify their importance in this pathology. These aspects are of great importance for professionals that act in the area of women's health.
}

key words

Vulvovaginal candidiasis

Candida albicans

Susceptibility factors

Virulence factors

1. Farmacêutica; pós-graduanda do Curso de Especialização em Análises Clínicas do Centro Universitário de Maringá (CESUMAR).

2. Professora-doutora de Micologia Médica do Curso de Farmácia, habilitação em Análises Clínicas na Universidade Estadual de Maringá (UEM).

3. Professora-doutora de Citologia Clínica do Curso de Farmácia, habilitação em Análises Clínicas na UEM. 


\section{Introdução}

O gênero Candida é constituído de aproximadamente 200 diferentes espécies de leveduras, que vivem normalmente nos mais diversos nichos corporais, como orofaringe, cavidade bucal, dobras da pele, secreções brônquicas, vagina, urina e fezes. Entre as espécies que compõem esse gênero, a Candida albicans apresenta maior relevância em função de sua taxa de prevalência em condições de normalidade e de doença ${ }^{(34,46,52)}$. Essa levedura está amplamente distribuída na natureza, ocupando diversos hábitats, ao contrário de outras espécies do gênero, de distribuição limitada ${ }^{(66)}$.

As leveduras do gênero Candida, em particular a C. albicans, são patógenos oportunistas freqüentemente isolados das superfícies mucosas de indivíduos normais ${ }^{(43)}$. Estão muito bem adaptadas ao corpo humano, por isso podem colonizá-lo sem produzir sinais de doença em condições de normalidade fisiológica ${ }^{(24)}$. Colonizam as mucosas de todos os seres humanos no decorrer ou pouco depois do nascimento, havendo sempre o risco de infecção endógena ${ }^{(3)}$. $\mathrm{O}$ delicado balanço entre o hospedeiro e esse fungo comensal pode-se transformar em uma relação parasitária, com o desenvolvimento de infecções denominadas candidíases( ${ }^{(8)}$. Essas infecções fúngicas variam desde lesões superficiais em pessoas sadias até infecções disseminadas em pacientes neutropênicos ${ }^{(13)}$. Um aumento na incidência de infecções fúngicas causadas por espécies de Candida tem sido observado em pacientes imunocomprometidos ${ }^{(22)}$.

C. albicans é um fungo dimórfico, que se apresenta sob formas leveduriformes (blastoconídios) no estado saprofítico, estando associado à colonização assintomática; ou como formas filamentosas (pseudo-hifas e hifas verdadeiras), observadas em processos patogênicos. Além disso, sob condições de crescimento subótimas, nesse fungo pode ocorrer a formação de clamidósporos (esporos arredondados que possuem uma espessa parede celular). Dessa forma, o fungo tem a capacidade de se adaptar a diferentes nichos biológicos, podendo ser considerado, a rigor, um organismo "pleomórfico" $(8,36)$.

Clinicamente, a candidíase pode ser cutânea, mucosa, cutaneomucosa ou visceral. O microrganismo cresce melhor em superfícies quentes e úmidas, causando freqüentemente vaginite, dermatite das fraldas e candidíase oral. Essas infecções são as manifestações usuais da doença e, embora normalmente não apresentem ameaça à vida, representam um problema de considerável importância socioeconômica. Formas cutaneomucosas severas são menos comuns, encaixando-se em duas grandes categorias: candidíase cutaneomucosa crônica e candidíase vaginal crônica. A primeira está geralmente associada a enfraquecimento da resposta imune mediada por células, como o observado em portadores do vírus da imunodeficiência humana (HIV) e indivíduos com defeitos imunológicos hereditários ou iatrogênicos. A segunda categoria é desencadeada por fatores de risco, como gestação, uso de contraceptivos orais, antibioticoterapia, diabetes mellitus (DM), entre outros. A candidíase disseminada intensa está associada a neutropenia secundária a doença granulomatosa crônica, leucemia, terapia antineoplásica ou imunossupressão após transplante. A Candida é diretamente introduzida no sangue por acessos intravenosos, cateteres, diálise peritoneal, cirurgia cardíaca ou abuso de drogas intravenosas. Essas observações sugerem que tanto as células fagocíticas quanto a resposta imune mediada por células específicas participam na defesa do hospedeiro contra o microrganismo ${ }^{(2,13)}$.

Antes da era dos antibióticos e corticóides, o número de infecções por fungos era bastante reduzido. Isso é particularmente verdade para as infecções por Candida, especialmente por $C$. albicans, que se apresentava como comensal, mas que, com as defesas comprometidas do indivíduo, se instala, invade tecidos e provoca danos. Concomitantemente, tem sido observada uma sensível elevação na freqüência de candidíase vulvovaginal (CVV) nos últimos anos, o que torna esse diagnóstico cada vez mais comum em ginecologia ${ }^{(12,68)}$.

Além de fatores inerentes ao hospedeiro, tem sido postulado que existem diferenças na patogenicidade de isolados de Candida sp. O fungo não é mero participante passivo no processo infeccioso; vários fatores de virulência são propostos, mas pouco investigados em CVV. Existem algumas propriedades ligadas às células de C. albicans, comumente denominadas fatores de virulência, que lhes conferem a capacidade de produzir doença. Esses atributos incluem adesão a substratos inertes e biológicos, formação de tubo germinativo com conseqüente desenvolvimento da forma filamentosa, variabilidade fenotípica (switching), variabilidade genotípica, produção de toxinas e enzimas extracelulares hidrolíticas, variabilidade antigênica, imunomodulação dos mecanismos de defesa do hospedeiro e hidrofobicidade de superfície celular, que constituem os fatores mais importantes para o desencadeamento de infecções ${ }^{(4,24)}$.

A CVV é atualmente um relevante problema na saúde da mulher, e profissionais atuantes nessa área têm a necessidade de conhecer aspectos atuais que estão sendo abordados sobre a sua patogenia, que possui ainda muitos aspectos 
para serem esclarecidos. Assim, o objetivo deste trabalho foi realizar levantamento bibliográfico para ampliar os conhecimentos sobre CVV e CVVR (candidíase vuvlvovaginal recorrente), bem como caracterizar e abordar o ponto de vista das influências do hospedeiro e dos fatores de virulência dos agentes causais da CVV, principalmente C. albicans, visando identificar a sua importância nessa patologia.

\section{Candidíase vulvovaginal}

CVV é um distúrbio ocasionado pelo crescimento anormal de fungos do tipo leveduras na mucosa do trato genital feminino. Trata-se de uma infecção de vulva e vagina, causada por leveduras comensais que habitam a mucosa vaginal bem como as mucosas digestiva e respiratória. Essas leveduras podem-se tornar patogênicas quando o sítio de colonização do hospedeiro passa a ser favorável ao seu desenvolvimento ${ }^{(68)}$. A CVV foi descrita pela primeira vez em 1949, por Wilkinson, que estabeleceu uma relação entre a existência de fungos na vagina e o aparecimento de vaginite. A partir desse momento, os conhecimentos foram evoluindo progressivamente.

A CVV é causada por fungos leveduriformes; a maioria deles pertencentes ao gênero Candida ${ }^{(68)}$. Oitenta por cento a $90 \%$ dos casos são devidos a C. albicans; $10 \%$ a $20 \%$, a outras espécies chamadas não-C. albicans (C. tropicalis, C. glabrata, C. krusei, C. parapsilosis, C. pseudotropicalis, C. lusitaniae). C. glabrata é a segunda espécie em freqüência nas $C V V^{(12,13,50,58)}$. Porém, leveduras de outros gêneros também podem causar essa infecção: Saccahromyces cerevisiae, Rhodutorula sp. e Trichosporon sp. ${ }^{10,14,20)}$.

Estudos mais recentes demonstram que em algumas populações a freqüência de isolamento de leveduras nãoC. albicans tem aumentado. No estudo de Ferraza et al. ${ }^{(20)}$, C. albicans foi a levedura mais isolada nas duas populações analisadas, porém em percentagens significativamente diferentes, uma do Paraná e outra de Santa Catarina. Em Santa Catarina representou $77,4 \%$ dos isolados; no Paraná, $50 \%$. O mesmo já havia sido descrito por um estudo italiano que demonstrou que a prevalência de CVV causada por leveduras não- C.albicans cresceu de 9,9\% em 1988 para 17,23\% em $1995^{(62)}$. A razão desse aumento não está ainda bem definida, sendo atribuída por alguns ao uso inadequado de antimicóticos ${ }^{(59)}$. Rosa et al. ${ }^{(53)}$ obtiveram uma freqüência de isolamento de $96 \%$ de C. albicans em material vaginal obtido em outra população de Santa Catarina, demonstrando que o aumento na freqüência de leveduras não-C. albicans não parece ser uma tendência geral.
Parecem existir também diferenças no que se refere ao isolamento de leveduras conforme o quadro clínico. Para Ferraza et al. ${ }^{(20)}$, em Santa Catarina C. albicans foi a mais prevalente nas duas condições clínicas, enquanto no Paraná o predomínio foi mais evidente nos casos sintomáticos (6/9) do que nos assintomáticos (6/15). Dan et al.(14) e Consolaro et al.(10) associaram a presença de sintomas ao isolamento de C. albicans, e leveduras não-C. albicans à sua ausência. Outros autores também têm associado espécies não-C. albicans à ausência de sintomas ou a vulvovaginites brandas ${ }^{(1,3)}$. Assim, apesar de C. albicans ser a levedura mais importante no trato genital feminino e o principal agente de CVV, estudos indicam que $20 \%$ a $25 \%$ das mulheres normalmente saudáveis e completamente assintomáticas apresentam culturas de secreção vaginal positivas para essa levedura, o que indica a importância da colonização vaginal prévia para o desenvolvimento da infecção ${ }^{(58)}$. Para Mattos et al. ${ }^{(42)}$, entre as pacientes colonizadas, pelo menos $50 \%$ apresentarão CVV em algum momento da sua vida.

A CVV é um dos diagnósticos mais freqüentes na prática diária em ginecologia e sua incidência tem aumentado drasticamente, tornando-a a segunda infecção genital mais freqüente nos Estados Unidos e no Brasil. A CVV representa $20 \%$ a $25 \%$ dos corrimentos vaginais de natureza infecciosa, precedida apenas pela vaginose bacteriana ${ }^{(12)}$. Na Europa, é a primeira causa de vulvovaginite ${ }^{(68)}$. Cavalcante et al..$^{(7)}$ reforçam em seu estudo a necessidade de valorizar a doença como importante causa de comprometimento da saúde da mulher. Estima-se que aproximadamente $75 \%$ das mulheres adultas apresentem pelo menos um episódio em sua vida, sendo que destas, $40 \%$ a $50 \%$ vivenciarão novos surtos e $5 \%$ atingirão o caráter recorrente (CVVR) ${ }^{(39)}$.

Essa infecção caracteriza-se por prurido, ardor, dispareunia e pela eliminação de um corrimento vaginal em grumos, semelhante à nata de leite. Com freqüência, a vulva e a vagina encontram-se edemaciadas e hiperemiadas, algumas vezes acompanhadas de ardor ao urinar e sensação de queimadura ${ }^{(57)}$. As lesões podem-se estender por períneo, região perianal e inguinal(1). O corrimento, que geralmente é branco e espesso, é inodoro e, quando depositado nas vestes a seco, tem aspecto farináceo. Em casos típicos, nas paredes vaginais e no colo uterino aparecem pequenos pontos branco-amarelados. Os sintomas se intensificam no período pré-menstrual, quando a acidez vaginal aumenta(54).

A principal fonte de leveduras vaginais é o trato gastrointestinal, através de um processo chamado transmissão endógena. Elas são veiculadas para a vagina por 
auto-inoculação, onde se adaptam e se desenvolvem. A transmissão sexual também é aceita, o que torna a CVV uma doença sexualmente transmissível (DST). Através da ação de enzimas como proteases e hidrolases, as leveduras que chegam à vagina penetram no seu epitélio superficial, ali permanecendo albergadas e podendo causar distúrbios imediatos ou constituir reservatório para reinfecções posteriores $^{(22)}$.

\section{Candidiase vulvovaginal recorrente}

Aproximadamente 5\% das mulheres com CVV desenvolvem CVVR, definida usualmente como a ocorrência de quatro ou mais episódios de CVV no período de 12 meses $^{(40,47)}$. Ao contrário das mulheres que têm episódios esporádicos de CVV, aquelas com a doença recorrente não se beneficiam de uma diminuição na freqüência de episódios sintomáticos com o passar da idade ${ }^{(40)}$.

A patogênese da CVVR entre mulheres que não têm condições predisponentes aparentes, que são a grande maioria, está sob investigação. Uma elevação na resistência de espécies de Candida não tem sido observada na maioria dos casos, embora se analisarmos essas pacientes como um grupo, mulheres com recorrência têm uma prevalência discretamente mais elevada de C. glabrata, menos sensível às drogas imidazólicas, comumente utilizadas no tratamento de CVV e CVVR(60).

\section{Fatores predisponentes do hospedeiro}

A expressão da relação parasita/hospedeiro depende do balanço entre a virulência do microrganismo e as defesas do hospedeiro. Como conseqüência, o tempo de incubação dificilmente pode ser precisado. Tanto fatores locais como sistêmicos podem contribuir para a invasão tecidual por C. albicans e por leveduras não-C. albicans. Sua intensa multiplicação no canal vaginal é favorecida por uma série de fatores predisponentes. Do ponto de vista do hospedeiro, a colonização prévia por levedura e a posterior diminuição da capacidade de resposta imunológica observada em doenças imunossupressoras, DM, gestantes e usuárias crônicas de corticóides parecem favorecer a infecção. Ainda parecem contribuir o uso de antibióticos, estrogenoterapia, pequenos traumas como o ato sexual, hábito de usar roupas muito justas ou de fibras sintéticas, além da dieta alimentar muito ácida ${ }^{(19,44)}$. A utilização de antibióticos pode incrementar tanto a colonização quanto a infecção por Candida. Embora diferentes estudos não tenham sido conclusivos nesse sentido, antibióticos podem suprimir a flora vaginal lactobacilar, que é o principal mecanismo defensivo vaginal contra os fungos ${ }^{(68)}$.

Na prática, a infecção vaginal por C. albicans geralmente é associada a situações de debilidade do hospedeiro ou aquelas em que o teor de glicogênio do meio vaginal está elevado e a conseqüente queda do $\mathrm{pH}$ local propicia o desenvolvimento da infecção. Qualquer alteração dos níveis de glicose, especialmente em situações de hiperglicemia, e qualquer estado em que se produz elevação do glicogênio vaginal podem desencadear $\mathrm{CV}^{(27)}$. O excesso de glicogênio aumenta o substrato nutritivo dos fungos, promovendo incremento na sua capacidade de adesão ${ }^{(35,48)}$. Altos níveis de produção de hormônios femininos, especialmente a progesterona, aumentam a disponibilidade de glicogênio no ambiente vaginal, o qual serve como excelente fonte de carbono para o crescimento e a germinação das leveduras $^{(57)}$. Raramente isola-se Candida na pré-menarca, fato que, associado à baixa prevalência CVV na menopausa, enfatiza a dependência hormonal da infecção(21). Como muitas mulheres são portadoras assintomáticas de Candida em pequenas quantidades, nesse estado a levedura é considerada comensal, e as alterações no ambiente vaginal do hospedeiro são necessárias para que ela induza aos seus efeitos patológicos e a paciente desenvolva CVV(58).

A microbiota vaginal normal é rica em lactobacilos produtores de peróxido (bacilos de Döderlein), os quais formam ácido lático a partir do glicogênio, presente principalmente no citoplasma das células escamosas do tipo intermediárias do epitélio vaginal, cuja produção é estimulada pelos hormônios sexuais femininos. Esse mecanismo propicia acidez adequada do ambiente vaginal ( $\mathrm{pH}$ em torno de 4,5), dificultando a proliferação da maioria dos patógenos. As leveduras são uma exceção, uma vez que proliferam em ambiente ácido ${ }^{(1)}$. A flora vaginal composta por lactobacilos constitui uma barreira defensiva importante à CVV, sendo que os lactobacilos atuam em três diferentes níveis. Em primeiro lugar, competem com os fungos pelos nutrientes. Em segundo, realizam um processo de co-agregação, podendo com isso, além de competir com os fungos, bloquear os receptores epiteliais para eles, inibindo a adesão dos mesmos ao epitélio vaginal. Esse mecanismo de defesa é o mais importante. Em terceiro lugar, são capazes de produzir substâncias (bacteriocinas) capazes de inibir a germinação de micélios. Isso talvez explique porque tratamentos com antibióticos podem desencadear CVV em decorrência da depleção da flora vaginal(68). 
C. albicans possui alta capacidade de se adaptar e crescer em extensão em situações de pH extremo. Assim, em $\mathrm{pH}$ neutro, tanto no fluxo sangüíneo como nos tecidos, o microrganismo expressa um gene (PHR1) cuja função está associada à síntese de parede e cuja expressão é ótima em pH próximo ao neutro. Uma vez que no canal vaginal a expressão de PHR1 é inibida, este é transformado em um segundo gene, também regulado por $\mathrm{pH}$, que produz função similar, mas em pH ácido (em torno de 2 a 4). Considerando tais fatos, essa levedura é um exemplo de adaptação em estados fisiológicos extremos, podendo estar presente em diversos sítios do hospedeiro(4).

Fatores predisponentes do hospedeiro já bem conhecidos, incluindo DM, imunossupressão, gravidez e terapias hormonais explicam apenas parcialmente a CVVR. O uso de antibióticos de amplo espectro, contraceptivo oral, dieta, higiene pessoal e práticas sexuais têm sido estudados como fatores de risco para recorrência ${ }^{(47)}$. A função de comportamentos específicos como risco para CVVR não é clara, mas algumas investigações implicam sexo oral e aumento na freqüência de intercurso sexual|(51).

Acredita-se que a CVVR esteja relacionada com uma depressão nos processos imunes da mucosa normal, o que permitiria certa "tolerância" da mucosa ao microrganismo. Pelo fato de ser encontrada alta incidência de CVVR em mulheres com imunidade celular (IC) prejudicada, como pacientes sob terapia com corticosteróides, transplantados ou pacientes portadores do vírus HIV, têm-se postulado que deficiências na IC específica contra Candida desempenhem papel importante na susceptibilidade à CVV primária e particularmente à CVVR. Por outro lado, o papel da imunidade humoral na proteção contra infecções fúngicas mucosas e sistêmicas permanece controverso. A maioria dos pacientes com infecções mucosas por $C$. albicans tem níveis normais ou elevados de anticorpos anti-Candida no soro e secreções mucosas( ${ }^{(22)}$. Apesar disso, evidências recentes demonstram que anticorpos com especificidades definidas mostram diferentes graus de proteção( 29,41$)$. Carvalho et al. ${ }^{(6)}$ demonstraram resposta acentuada de $\lg \mathrm{A}, \lg \mathrm{G} 1$ e $\lg \mathrm{G} 4$ anti-C. albicans no lavado vaginal de mulheres sintomáticas com cultura positiva, sugerindo importante papel desses anticorpos na resposta imune local estimulada pela presença do fungo. O mecanismo exato pelo qual esses anticorpos protegem contra infecções por Candida é desconhecido, mas parece incluir inibição da adesão ou formação do tubo germinativo, opsonização, neutralização de enzimas relacionadas com a virulência e atividade fungicida direta ${ }^{(43)}$.

\section{Fatores de virulência de leveduras}

A patogenicidade ou virulência de um microrganismo é definida como sua capacidade de determinar doença, que é mediada por múltiplos fatores. Apesar de certos aspectos da virulência serem determinados geneticamente, eles são expressos pelos microrganismos apenas quando existem condições ambientais favoráveis, tais como teor nutricional, atmosfera de oxigênio e temperatura. Essas condições são específicas para cada microrganismo e para cada isolado de determinado agente. Podem variar de hospedeiro para hospedeiro e mesmo entre os diferentes tecidos de um mesmo hospedeiro ${ }^{(24)}$. Os principais fatores de virulência de leveduras são descritos a seguir.

\section{Aderência}

Nem sempre todas as etapas de virulência são cumpridas por um microrganismo, sendo requisito básico para o estabelecimento de uma infecção que o patógeno entre em contato com a camada que recobre a superfície epitelial da mucosa do hospedeiro. A aderência permanente entre o microrganismo invasor e o tecido do hospedeiro requer o estabelecimento de ligações específicas entre estruturas complementares existentes na superfície do patógeno e da célula epitelial(24).

O evento inicial na patogênese de doenças infecciosas é a adesão microbiana aos tecidos hospedeiros. Alguns microrganismos não-invasivos permanecem aderidos à superfície hospedeira, enquanto outros utilizam essa adesão como a primeira etapa para a invasão tecidual. A adesão de patógenos à superfície de células eucarióticas é mediada por macromoléculas denominadas adesinas (estruturas da superfície do microrganismo que interagem com receptores específicos nas células eucarióticas). Um microrganismo pode expressar uma ou mais adesinas, e essa expressão é regulada por fatores ambientais ou do hospedeiro ${ }^{(23)}$.

Existem evidências de que $C$. albicans pode produzir mais de uma estrutura adesiva, sendo que a uma manoproteína está primariamente atribuída a função adesiva nas reações de adesão(17). Nos últimos anos foi reconhecida a importância da compreensão do processo de adesão microbiana, particularmente no nível bacteriano, havendo necessidade de estudos mais aprofundados sobre leveduras, em particular as isoladas de secreção vaginal(31).

Devido à importância da aderência, alguns estudos in vivo e in vitro têm sido desenvolvidos para quantificar e caracterizar a aderência de $C$. albicans a superfícies celulares e inanimadas ${ }^{(31,56)}$. A ligação de C. albicans a superfícies 
mucosas tem sido demonstrada como um importante passo no processo infeccioso, particularmente na cavidade oral e na mucosa vaginal(31).

Estuda-se também a aderência de um microrganismo avaliando a sua capacidade de formar biofilmes (um outro tipo de aderência, na qual os microrganismos formam agregados unicelulares, gerando estruturas multicelulares que aderem a superfícies). Sua formação ocorre em resposta a uma variedade de condições, incluindo alta densidade celular, privação de nutrientes e estresse físico ambiental ${ }^{(45)}$.

Em CVV, a avaliação da capacidade de formação de biofilme é importante devido à possibilidade de sua ocorrência em dispositivos intra-uterinos (DIU). Porém, apresenta-se também importante nas CVV e CVVR não relacionadas a DIU, já que algumas células fúngicas na mucosa vaginal podem existir com uma mistura de espécies formando biofilmes, inclusive com bactérias da flora vaginal. Essas leveduras têm maior resistência à terapia antifúngica convencional e isso pode ser responsável pela não-erradicação da C. albicans do lúmen vaginal, explicando, pelo menos em parte, a ocorrência de CVVR ${ }^{(18)}$.

\section{Hidrofobicidade de superfície celular}

Já é conhecido que células leveduriformes hidrofóbicas (CSH) são mais virulentas em ratos do que células leveduriformes hidrofílicas. A expressão de CSH por C. albicans tem sido relacionada com virulência aumentada, provavelmente por estimular fenômenos de aderência, resistência à fagocitose e germinação ${ }^{(30)}$. Embora o mais forte mecanismo envolvendo a aderência esteja provavelmente relacionado com uma adesina manoproteína de C. albicans, CSH tem sido descrita por vários investigadores como envolvida na aderência ${ }^{(31)}$.

\section{Produção de tubos germinativos}

A habilidade de transição morfológica de C. albicans tem sido sugerida como importante fator de virulência ${ }^{(28)}$. As hifas têm maior capacidade de aderir e penetrar nas células epiteliais humanas do que os blastoconídios ${ }^{(28,46)}$. Mutantes incapazes de produzir hifas perdem a virulência de seus parentais ${ }^{(37)}$. Segundo Chaffin et al. ${ }^{(8)}$, essas transições representam uma resposta do fungo a alterações nas condições ambientais e possibilitam a sua adaptação a diferentes nichos biológicos, e a conseqüente disseminação fúngica nas células humanas. Essas evidências reforçam a idéia de que a habilidade de formar hifas representa importante função na patogênese de $C$. albicans. Porém, poucos estudos têm sido realizados objetivando verificar se há relação entre a capacidade de formar tubos germinativos e a virulência de C. albicans em CVV, especialmente em relação à CVVR. Consolaro et al.(11) mostraram recentemente a associação entre sinais clínicos de CVV e a produção de tubos germinativos pela levedura.

\section{Produção de exoenzimas}

Várias substâncias produzidas por C. albicans têm sido associadas a infecção, ou seja, consideradas fatores de virulência. Segundo Wain et al. ${ }^{(64)}$, as infecções por esse microrganismo estão relacionadas diretamente com a produção de exoenzimas. Atualmente, elas têm sido consideradas um dos mais importantes fatores de virulência de C. albicans ${ }^{(15}$, 25). Tem sido referido que proteinases extracelulares estão envolvidas na virulência da C. albicans ${ }^{(15,16,55)}$. Espécies mutantes de C. albicans, com capacidade de secreção de proteinases deficiente ou diminuída, são menos virulentas que as demais ${ }^{(38)}$. As enzimas do tipo fosfolipase também estão associadas à virulência de C. albicans ${ }^{(25,65)}$. Contudo, pouco foi concluído sobre o papel dessas exoenzimas na patogênese da CVV.

\section{Variabilidade genotípica}

O estudo da variabilidade genotípica tem sido possível graças aos recentes avanços em biologia molecular. Através da análise do DNA genômico, Candida sp. podem ser classificadas no nível de subespécies, sendo esses dados muito utilizados em investigações epidemiológicas. Entre os sistemas de tipagem molecular utilizados para discriminar isolados de C. albicans, pode-se destacar o polimorfismo de fragmentos de DNA obtidos com enzimas de restrição( ${ }^{(49,63,67)}$.

Vários estudos genéticos têm determinado que, na maioria dos casos de CVVR, um único isolado tem sido responsável pelos episódios sintomáticos seqüenciais. Porém, a levedura causal pode ser substituída algumas vezes ${ }^{(5,13,61)}$. Apesar disso, estudos de virulência de C. albicans com alta similaridade genética em episódios seqüenciais de CVVR não têm sido realizados.

\section{Tigmotropismo e internalização}

O estágio inicial da infecção a superfícies mucosas pelas formas filamentosas de C. albicans é conhecido como tigmotropismo, que consiste em um contato guiado, em adição à liberação de várias enzimas hidrolíticas, sendo a mais importante nesse caso a fosfolipase ${ }^{(32)}$. Embora não fagocíticas, culturas de células epiteliais vaginais e bucais exibem um fenômeno chamado "internalização celular" de organismos 
e apresentam uma fagocitose atípica. Entretanto, tem sido reportado que blastósporos de C. albicans, independente de sua viabilidade, são hábeis para induzir fagocitose em cultura de células endoteliais( ${ }^{(32)}$. Apenas as pontas das hifas em crescimento e não os blastósporos parecem penetrar diretamente na superfície das células epiteliais (internalização) e em suas junções (tigmotropismo), parecendo que um mecanismo não predomina sobre o outro para penetração nos tecidos pelas leveduras ${ }^{(32,33)}$.

\section{Switching fenotípico}

Significa alteração fenotípica na morfologia das colônias de C. albicans. Normalmente existem várias diferenças entre as colônias que apresentam switching e as demais, incluindo mudança no formato, estruturas de superfície celular e germinação a $37^{\circ} \mathrm{C}$, que parecem ser mais virulentas. Genes diferenciais induzidos por hemoglobina de proteínas fibronectina-ligantes têm sido parcialmente caracterizados ${ }^{(4)}$.

\section{Discussão e conclusão}

Este artigo de revisão bibliográfica buscou atualizar os profissionais da área da saúde em relação a CVV, CVVR, aspectos predisponentes do hospedeiro e virulência dos agentes causais. Os fatores predisponentes do hospedeiro são bastante estudados e conseqüentemente conhecidos, ao menos em parte, pelos profissionais que trabalham com a saúde da mulher. Entretanto, aspectos ligados aos agentes patológicos, que são as leveduras, são pobremente conhecidos. Visto que essa infecção é considerada atualmente importante problema de saúde pública, torna-se muito salutar que profissionais atuantes nessa área conheçam ambos os aspectos de maneira atualizada em relação à patogenia da CVV. Assim, a atualização e o conhecimento de conceitos básicos e clínicos relacionados com essa patologia são muito importantes para auxiliar no manejo dessa infecção pelos profissionais da área.

\section{Referências}

1. ALMEIDA FILHO, G.L.; PASSOS, M.R.L.; GOUVÊA, T.V.D. Candidíase. In: PASSOS, M.R.L. Doenças sexualmente transmissíveis. 4 ed. Rio de Janeiro: Cultura Médica, 1995.

2. ASHMAN, R.B.; PAPADIMITRIOU, J.M.. Production and function of cytokines in natural and acquired immunity to Candida albicans infection. Microbiol Rev, v. 59, p. 646-72, 1995.

3. BROOKS, G.F.; BUTEL, J.S.; MORSE, S.A. Jawetz, Melnick \& Adelberg Microbiologia Médica. 21 ed. Rio de Janeiro: Guanabara-Koogan, 2000.

4. CALDERONE, R.A.; FONZI, W. Virulence factors of Candida albicans. Trends Microbiol, v. 9, n.7, p. 327-31, 2001.

5. CARDONA-CASTRO, N. et al. Proteinase detection, DNA typing and antimycotic susceptibility of Candida isolates from Colombian women with vulvovaginal candidiasis. Rev Iberoam Micol, v. 19, p. 89-94, 2002.

6. CARVALHO, R.J.V. et al. IgA, IgE e subclasses de IgG antiCandida albicans no soro e lavado vaginal de pacientes com candidíase vulvovaginal. Rev Assoc Med Bras, v. 49, n. 4, p. 42-30, 2003.

7. CAVALCANTE, V.L.N.; MIRANDA, A.T.; PORTUGAL, G.M.P. Rastreamento de candidose vaginal durante a prevenção do câncer cérvico-uterino. DST - J Bras Doenças Sex Transm, v. 17, n. 1, p. 44-48, 2005.

8. CHAFFIN, W.L. et al. Cell wall and secreted proteins of Candida albicans: identification, function, and expression. Microbiol Molec Biol Rev, v. 62, p. 130-80, 1998.

9. CHONG, P.P. et al. Genetic relatedness of Candida strains isolated from women with vaginal candidiasis in Malaysia. J Med Microbiol, v. 52, p. 657-66, 2003.

10. CONSOLARO, M.E.L. et al. Correlation of Candida species and symptoms among patients with vulvovaginal candidiasis in Maringá, Paraná, Brazil. Rev Iberoam Micol, v. 21, p. 202-05, 2004.

11. CONSOLARO, M.E.L. et al. Vulvovaginal candidiasis is associated with the production of germ tubes by Candida albicans. Mycopathol,v. 159, p. 501-07, 2005.

12. CORSELLO, S. et al. An epidemiological survey of vulvovaginal candidiasis in Italy. Eur J Obstet Gyenecol Reprod Biol, v. 110, p. 66-72, 2003.

13. COTRAN, R.S.; KUMAR, V.; COLLINS, T. Robbins. Patologia estrutural e funcional. 6 ed. Rio de Janeiro: Guanabara-Koogan, 2000.

14. DAN, M.; POCH, F.; LEVIN, D. High rate of vaginal infections caused by non-C. albicans Candida species among asymptomatic women. Med Mycol, v. 40, p. 383-86, 2002.

15. DE BERNANRDIS, F.; SULLIVAN, P.A.; CASSONE, A. Aspartyl proteinases of Candida albicans and their role in patogenicity. Med Mycol, v. 39, p. 303-13, 2001.

16. DOSTÁL, J. et al. Simple method for screening Candida species isolates for the presence of secreted proteinases: a tool for the prediction of successful inhibitory treatment. J Clin Microbiol, v. 41, p. 712-16, 2003.

17. DOUGLAS, L. J. Adhesion of pathogenic Candida species to host surfaces. Microbiol Sci, v. 2, p. 243-47, 1985. 
18. DOUGLAS, L.J. Candida biofilms and their role in infection. Trends Microbiol, v. 11, p. 30-36, 2003.

19. FERNANDES, C.E.; MACHADO, R.B. Aspectos etiopatogênicos, diagnósticos e terapêuticos da candidíase vulvovaginal. Rev Bras Med, v. 7, p. 100-4, 1996.

20. FERRAZA, M.H.S.H. et al. Caracterização de leveduras isoladas da vagina e sua associação com candidíase vulvovaginal em duas cidades do sul do Brasil. RBGO, v. 27, n. 2, p. 58-63, 2005.

21. FERRER, J. Vaginal candidosis: epidemiological and etiological factors. Int Journal Gynaecol Obstet, v. 71, p. 21-27, 2000.

22. FIDEL Jr., P.L; SOBEL, J.D. Immunopathogenesis of recurrent vulvovaginal candidiasis. Rev Clin Microbiol, v. 9, p. 335-48, 1996.

23. FINLAY, B.B.; FALKOW, S. Common themes in microbial pathogenicity. Microbiol Rev, v. 53, p. 210-30, 1989.

24. GHANNOUM, M.A.; RADWAN, S.S. Candida adherence to epithelial cells. New York: CRC Press, 1990.

25. GHANNOUM, M.A. Potential role of phospholipases in virulence and fungal pathogenesis. Clin Microbiol Rev, v. 13, p. 122-43, 2000.

26. GOMPEL, C.; KOSS, L.G. Citologia ginecológica e suas bases anatomoclínicas. São Paulo: Manole, 1997.

27. GOSWAMI D, G.R. et al. Pattern of Candida species isolated from patients with diabetes mellitus and vulvovaginal candidiasis and their response to single dose oral fluconazole therapy. Antimicrob Agents Chemother, v. 49, n. 6, p. 2336-42, 2005.

28. HAMMER, K.A.; CARSON, C.F.; RILEY, T.V. Malaleuca alternifolia (tea tree) oil inhibits germ formation by Candida albicans. Med Mycol, v. 38, p. 355-62, 2000.

29. HANN, Y.; MORRISON, R.P.; CUTLER, J.E. A vaccine and monoclonal antibodies that enhance mouse resistance to Candida albicans vaginal infection. Infect immune, v. 66, p. 5771-76, 1998.

30. HAZEN, K.C.; WU, J.G.; MASUOKA, J. Comparison of hydrophobic properties of Candida albicans and Candida dubliniensis. Infect Immun, v. 69, p. 779-86, 2001.

31. JABRA-RIZKI, M.A. et al. Cell surface hydrophobicityassociated adherence of Candida dubliniensis to human buccal ephitelial cells. Rev Iberoam Micol, v. 18, p. 17-22, 2001

32. JAYATILAKE, J.A.M.S; SAMARANAYAKE, Y.H.; SAMARANAYAKE, L.P. An ultrastructural and a cytochemical study of candidal invasion of reconstituted human oral epithelium. J Oral Med, v. 34, p. 240-46, 2005.

33. KRAUTGARTNER, V.L. et al. Candida attachment to oral epithelium. Oral Microbiol Immunol, v. 17, p. 60-4, 2002.

34. KURTZMANN, C. P.; FELL, J. W. The Yeast: a taxonomic study. $4^{\text {th }}$ ed. Amsterdam: Elsevier, 1998.

35. LACAZ, C.S. Candidíases. São Paulo: Editora da Universidade de São Paulo, 1980.

36. LACAZ, C.S; PORTO, E.; MARTINS, J.E.C. Micologia médica: fungos, actinomicetos e algas de interesse médico. 8 ed. São Paulo: Sarvier, 1991.
37. LO, H. et al. Nonfilamentous Candida albicans mutants are avirulent. Cell, v. 90, p. 939-49, 1997.

38. Mac DONALD, F.; ODDS, F.C. Virulence for mice of a proteinase: secreting strain of Candida albicans and a proteinase-deficient mutant. J Microbiol, v. 129, p. 431, 1983.

39. MARDH, P.A. et al. Facts and myths on recurrent vulvovaginal candidosis: a review on epidemiology, clinical manifestations, diagnosis, pathogenesis and therapy. Int J STD AIDS, v. 13, p. 522-39, 2002.

40. MARRAZZO, J.M. Vulvovaginal candidiasis: over the counter doesn't seem to lead to resistance. BMJ, v. 326, p. 993-94, 2003.

41. MATTHEWS, R.; BURNIE, J. Antifungal antibodies a new approach to the treatment of systemic candidiasis. Curr Opin Investig Drugs, v. 2, p. 472-76, 2001.

42. MATTOS, A.H.S. et al. Prevalência de leveduras do gênero Candida em secreção vaginal. Rev Bras Ginecol Obst, v. 15, n. 4, p. 163-66, 1993.

43. MORAGUES, M.D. et al. A monoclonal antibody directed against a Candida albicans cell wall mannoprotein exerts three anti- $C$ albicans activities. Infec Immun, v. 71, p. 5273-79, 2003.

44. NARDIN, M.E. et al. Prevalencia de la candidiasis vulvovaginal y su relación con algunos factores de riesgo. Rev Argent Microbiol, 2000.

45. O'TOOLE, G.A.; KAPLAN, H.B.; KOLTER, R. Biofilm formation as microbiol development. Ann Rev Microbiol, v. 54, p. 49-79, 2000.

46. ODDS, F.C. et al. Candida concentrations in the vagina and their association with signs and symptoms of vaginal candidosis. J Med Vet Mycol, v. 26, p. 277-83, 1988.

47. PATEL, D.A. et al. Risk factors for recurrent vulvovaginal candidiasis in women receiving maintenance antifungal therapy: results of a prospective cohort study. Am J Obst Gyn, v. 190, p. 644-53, 2004.

48. PEREIRA, I.D.B. et al. Vulvovaginites por Candida albicans em pacientes ambulatoriais do Hospital Universitário Betina Ferro de Souza. Rev Bras Anál Clin, v. 28: 53-4, 1996.

49. PFALLER, M.A. Epidemiological typing methods for mycoses. Clin Infect Dis, v. 14, p. 4-10, 1992.

50. PICHOVÁ, I. et al. Secreted aspartic proteinases of Candida albicans, Candida tropicalis, Candida parapsilosis and Candida lusitaniae: inhibition with peptidomimetic inhibitors. Eur J Biochem, v. 268, p. 2669-77, 2001.

51. REED, B.D. et al. Sexual behavior and other risk factors for Candida vulvovaginitis. J Womens Health Gend Based Med, v. 9, p. 645-55, 2000.

52. RIPPON, J.W. Medical micology. The pathogenic fungi and the pathogenic actinomycetes. Philadelphia: Saunders, 1974.

53. ROSA, M.I.; RUMEL, D. Fatores associados à candidíase vulvovaginal: estudo exploratório. Rev Bras Ginecol Obstet, v. 26, n. 1, p. 65-70, 2004.

54. SALVATORE, C.A. Candidíase vulvovaginal. In: LACAZ, C.S. Candidíases. São Paulo: Editora da Universidade de São Paulo, 1980.

55. SCHALLER, M. et al. The secreted aspartyl proteinases Sap 1 and Sap 2 cause tissue damage in an in vitro model of vaginal candidiasis based on reconstituted 
human vaginal epithelium. Infect Immun, v. 71, p. 3227-34, 2003.

56. SHIN, J.H. et al. Biofilm production by isolates of Candida species recovered from nonneutropenic patients: comparison of bloodstream isolates with isolates from other sources. J Clin Microb, v. 40, p. 1244-56, 2002.

57. SOBEL, J.D. Vaginal infections in adult women. Med Clin North Am, v. 74, p. 1575-602, 1990.

58. SOBEL, J.D. Candidal vulvovaginitis. Clin Obstet Gynecol, v. 36, p. 153-12, 1993.

59. SOBEL, J.D. Vulvovaginitis due to Candida glabrata: an emerging problem. Mycoses, v. 41, suppl. 2, p. 18-22, 1998.

60. SOBEL, J.D. et al. Treatment of complicated Candida vaginitis: comparison of single and sequential doses of fluconazole. Am J Obstet Gynecol, v. 185, p. 363-9, 2001.

61. SOLL, D.R. Candida commensalism and virulence: the evolution of phenotypic plasticity. Acta Tropica, v. 81, p. 101-10, 2002.

62. SPINILLO, A. et al. Recurrent vaginal candidiasis: results of a cohort study of sexual transmission and intestinal reservoir. J Repro Med, v. 37, p. 343-47, 1992.

63. SULLIVAN, D. et al. Oligonucleotide fingerprinting of isolates of Candida species other than C. albicans and of atypical Candida species from human immunodeficiency virus-positive and AIDS patients. J Clin Microbiol, v. 31, p. 2124-33, 1993.

64. WAIN, W.A.; PRICE, F.M.; CAWSON, R.A. Factors affecting plague formation by Candida albicans infecting chick chorio-allantoic membrane. Sabour, v. 14, p. 149-54, 1976.

65. WHITE, T.C.; MIYASAKI, S.H.; AGABIAN, N. Three distinct secreted aspartyl proteinase in Candida albicans. J Bacteriol, v. 175, p. 6126-33, 1993.

66. WINNER, H. S.; HURLEY, R. Candida albicans. London: Churchill, 1964.

67. WILKINSON, B. M. et al. A new sensate polynucleotide probe for distinguishing Candida albicans strains and its use with a computer-assisted archiving and pattern comparison system. J Med Vet Mycol, v. 30, p. 123-31, 1992.

68. ZIARRUSTA, G.B. Vulvovaginitis candidiásica. Rev Iberoam Micol, v. 19, p. 22-4, 2002. 